\title{
Airborne Geophysical Survey in Kosova
}

\author{
Mr.sc Xhevdet Kastrati* and Mr Sc. Ramiz Krasniqi \\ Independent Commission for Mines and Minerals, Kosova Rr. Armend Daci Nr.1 Prishtinë. 10000 prishtn, Kosovo
}

\begin{abstract}
The airborne geophysical survey in Kosova is a very important project, which has been conducted during 2006-2007, according to the terms of references processed by the ICMM (International Council on Mining and Metals). The airborne geophysical survey in Kosova is carried out by the British Geological Survey and the Geological Survey of Finland. The geophysical survey is carried out for three components. There are provided the important data with the images of electromagnetic, magnetic and radiometric components. The ICMM possesses the necessary software, which enables the giving of geophysical data for mining companies, according to the specified coordinates and respective components. The GPS are used to determine the exact location of each mining source, gaining coordinates in area $(\mathrm{x}, \mathrm{y}, \mathrm{z})$. The method GPS has accelerated and facilitated the works of project. The same system has been used also by the company of geographic survey.
\end{abstract}

Key words: The airborne geophysical survey, GPS, GIS.

\section{Introduction}

The survey has achievements in the identification of many useful minerals to be exploited.

The airborne geophysical survey in Kosova is carried out by the Geological Survey of Finland and the British Geological Survey. The geophysical survey is carried out for three components.

In this study there are used the data from the airborne geophysical Survey carried out by two Geological surveys with 172 years of experience and also the data from the ICMM (International Council on Mining and Metals) archive where the survey is kept.

The reason of survey is the new methodology of study that it is applied for the first time in Kosova in the exploration of minerals by air.

The importance of survey is the identification of zones of interest with useful minerals.

\section{Technical Programs}

To ensure that Kosovo's mineral potential is adequately promoted and developed, the ICMM has undertaken numerous technical programs, where most important are viewed to be:

\footnotetext{
*Corresponding author: Mr.sc Xhevdet Kastrati. E-mail:
} Xhevdet.Kastrati@kosovo-mining.org; xkastrati01@gmail.com.
(1) GeoScientific Maps;

(2) Explosives Security System;

(3) Kosova Quarry Plan;

(4) Geochemical Survey;

(5) Airborne Geophysical Survey;

(6) Geographical Information System.

\section{Materials and Methods}

By this study, the important data are provided with the images of electromagnetic, magnetic and radiometric components, which are taken by the airborne method through softwares to get data and softwares to receive data, where the images are created with data on metals based on magnetic characteristics and resistance of metallic material, where geophysical, electrical, magnetic method are used.

A great number of geological maps with images on great potentials with minerals of Kosova have been created from this survey:

Equipments on flying with softwares for data collection;

Demonstration of work and equipments in this survey.

ICMM Geoscientific map technical program resulted with a series of 1:200,000 scale maps that show following features: 


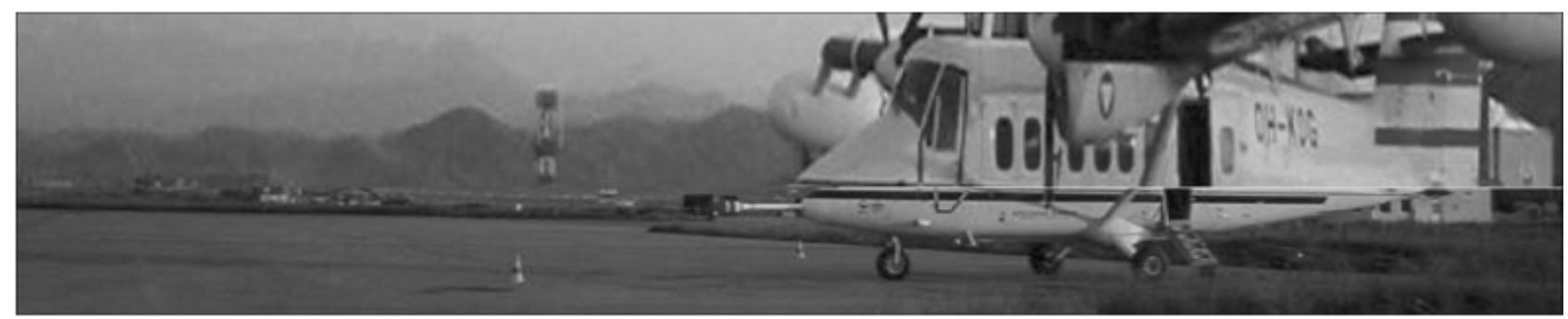

Fig. 1 View of airborne geophysical survey.

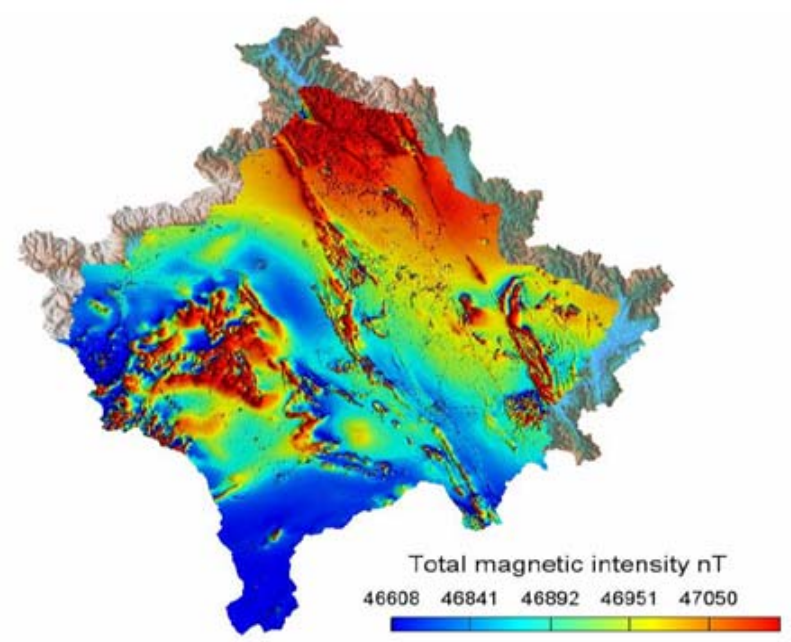

Fig. 2 Results of airborne geophysical survey-images in maps.

(1) Geological Map of Kosova;

(2) Tectonic Map of Kosova;

(3) Map of Minerals of Kosova;

(4) Hydrogeological Map of Kosova;

(5) Map of Mineral - And Thermal water of Kosova;

(6) Morpho-Orographical Structure of Kosova;

(7) Soil Map of Kosova;

(8) Satellite Imagery Map of Kosova.

\subsection{Airborne Geophysical Survey}

The JAC (Joint Airborne-Geoscience Capability) established between the GTK (Geological Survey of Finland) and BGS (British Geological Survey), carried out the survey under contract to the ICMM.

$$
\mathrm{R}=1 / 2 \mathrm{TI} \text { f c }
$$

Airborne survey method is carried out by geophysics methods and incorporation of GPS system to determinate the location exactly by coordinates where it is done the identification of the zones of interest, orientation in appropriate and exact location for detail exploration by drilling and sampling.

The GPS is used to determine the exact location of each mining source, gaining coordinates in area $(\mathrm{x}, \mathrm{y}, \mathrm{z})$.

The airborne geophysical data were collected in 2006 (Phase 1) and 2007 (Phase 2) by the co-operative team JAC, using a Twin-Otter fixed-wing aircraft.

The survey is being conducted at high resolution. East-West flight lines were $200 \mathrm{~m}$ apart and a nominal drape of $30 \mathrm{~m}$ is maintained wherever possible. The project involved flying $>$ 50,000 line-km.

There were three sets of data collected:

(1) Magnetic data;

(2) Electromagnetic data;

(3) Radiometric data.

\subsubsection{Magnetic Data}

In overview, the MAG (Magnetic data) respond to both at-surface and concealed magnetic rocks at all depths (a wavelength dependence). The variation in magnetic texture can be used to assist in identifying different rock types, because the magnetic signature mirrors mineral texture and fabrics or fracturing style of the source rock.

\subsubsection{Electromagnetic Data}

The EM (Electromagnetic) data comprise coupling ratios, which are converted to provide a measure of the bulk subsurface conductivity. The bulk conductivity in near-surface materials is largely dependent on geology (i.e. mineralogy) and the electrical conductivity of pore fluids. The system provides sensitivity to conductivity changes to depths of typically between 60 and $100 \mathrm{~m}$.

3.1.3 Radiometric Data

The RAD (Radiometric data) respond to about 


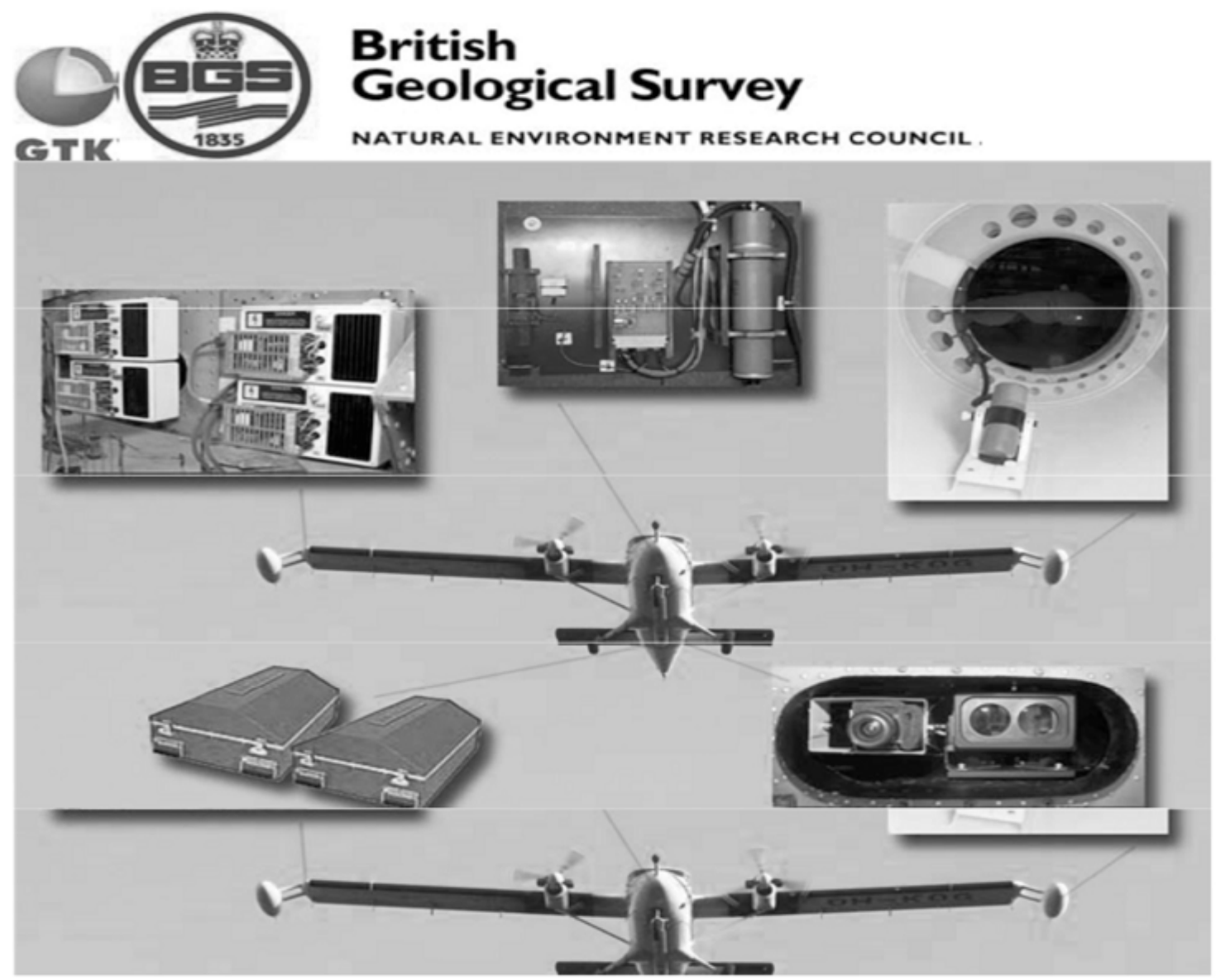

Fig. 3 Work equipments used in field during airborne geophysical survey the work demonstration of GTK and BGS.

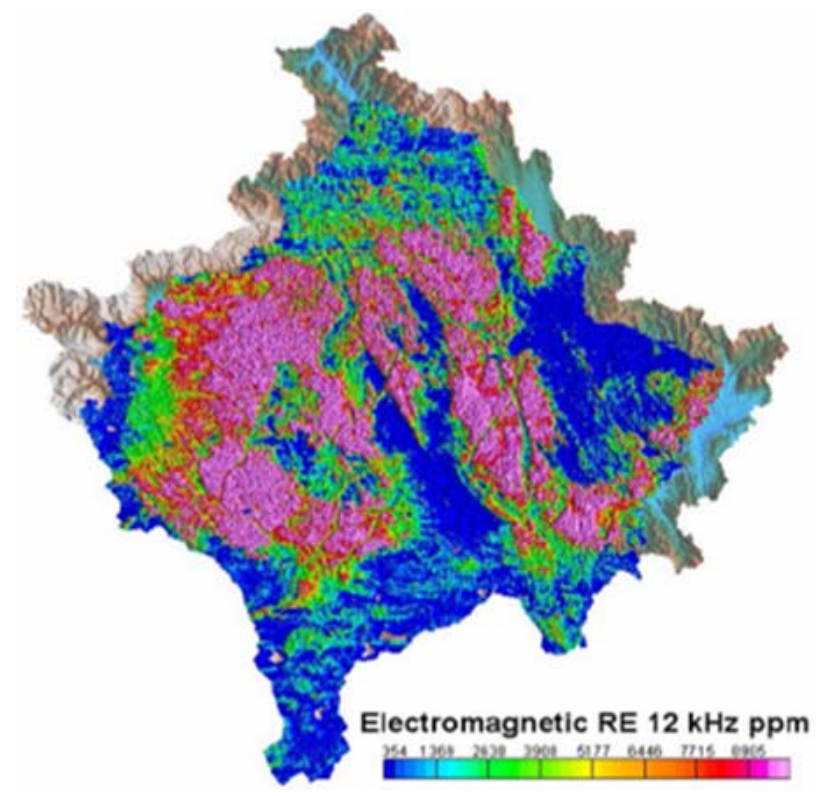

Fig. 4 Magnetic Survey Map.

$30-50 \mathrm{~cm}$ of the radiometric content of the surface material and reflect the lithological variation and the background response of natural radioactivity. Three individual natural radionuclide elements - Potassium (K-40), Thorium (Th-232) and Uranium (U-238) may be examined.

\subsection{Geo Database Kosovo (GDK)}

Starting in 2003, the ICMM has developed the GDK (Geo Database Kosovo) information management system. The information system can only be described as "state of the art", and it is a system of which Kosovo is justly proud. The system among many other issues, deals with the following issues and can be accessed on line:

Mining Law administrative issues (handling of exploration and exploitation licences, blasting permits, processing plant operation permits, persons and companies).

Document handling (“paperless office”) - all relevant 


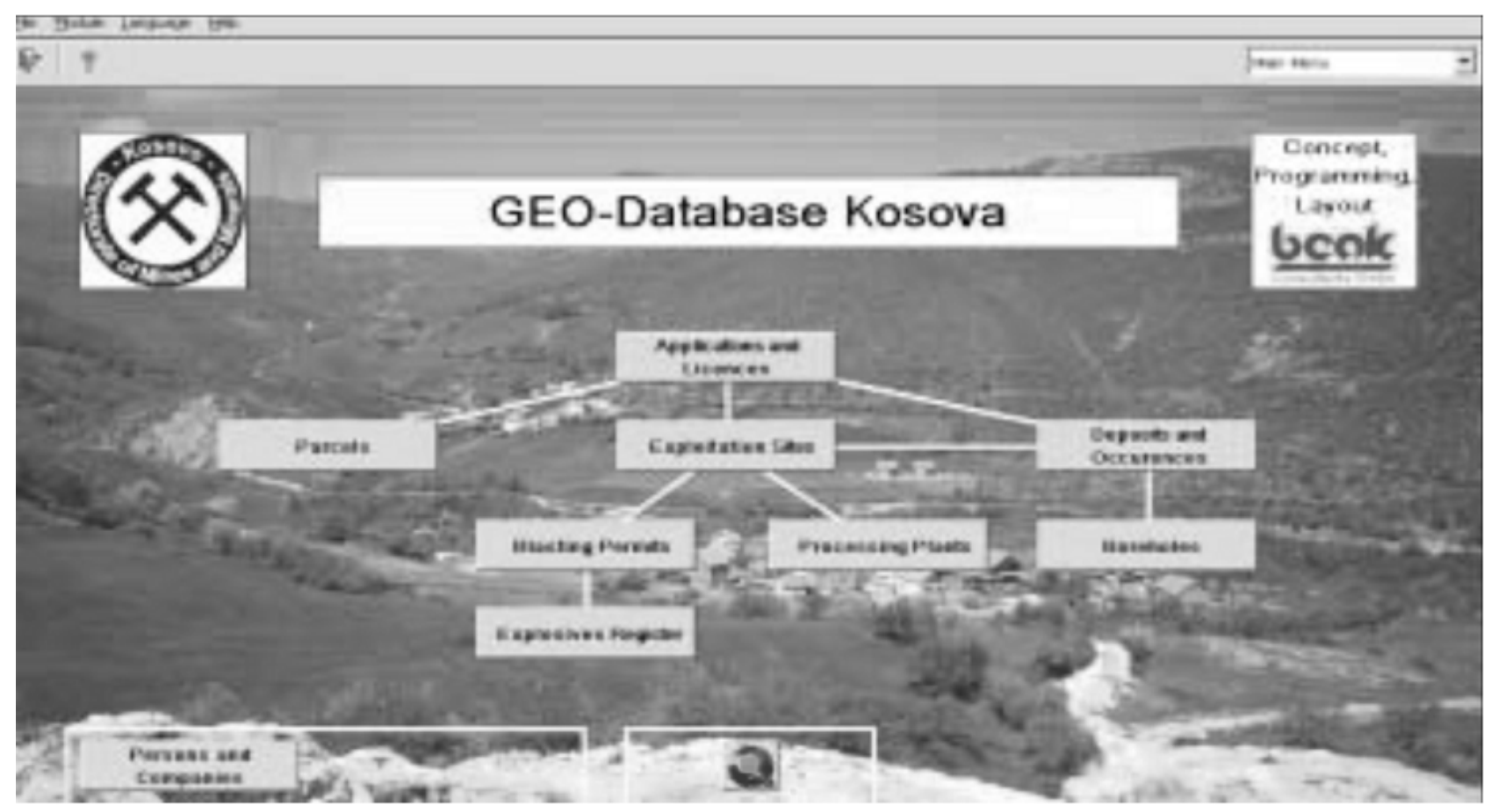

Fig. 5 Geo Database Kosovo (GDK).

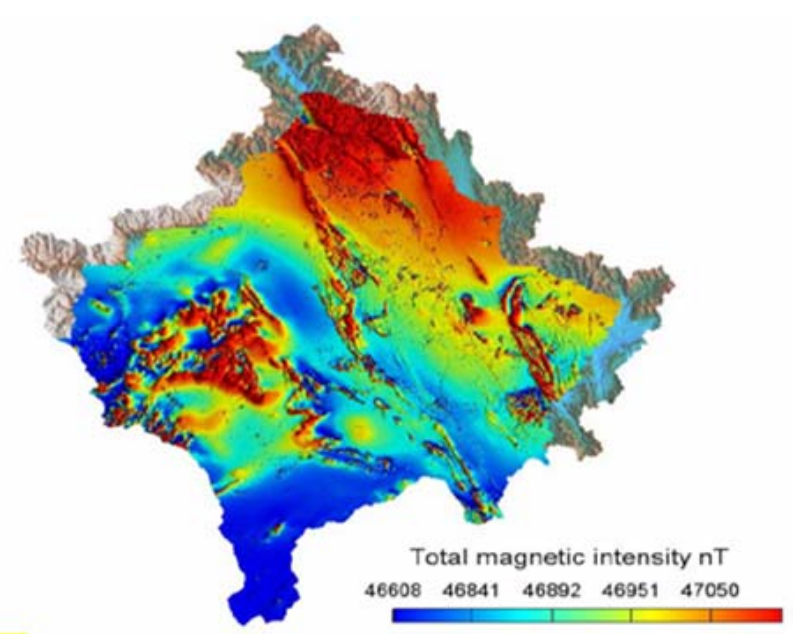

Fig. 6 Zones of interest.

documents have to be visible on screen.

Storage of all mineral relevant information (e.g. deposits and occurrences).

Management of factual geoscientific data (boreholes, samples, geochemical analyses, geophysical data and contaminated sites).

Preparation of geoscientific maps - interactive digital geological maps, soil maps and minerals maps. We strongly encourage potential investors and exploration companies to visit the ICMM web site and offices to assess this mining and geological management information system.

\section{Results and Discussion}

Kosovo has been surveyed that possesses minerals resources, particularly lead, zinc, lignite, ferronickel, bauxites, etc.

Kosova is open to further explore its mineral resources. Kosova's mining and minerals sector is very attractive for everybody.

As a result of Airborne Geophysical Survey, the zones are localized in the Kosova territory by which can be continued with detailed surveys by drillings.

From this study the results are gained in creation of a database and also the determination of the zones of interest for detail exploration.

\subsection{Zones of Interest}

In principle, there are three ways obtaining an exploration/exploitation license in Kosovo:

(a) First come, first served;

(b) Competitive tendering;

(c) Mine development agreement. 


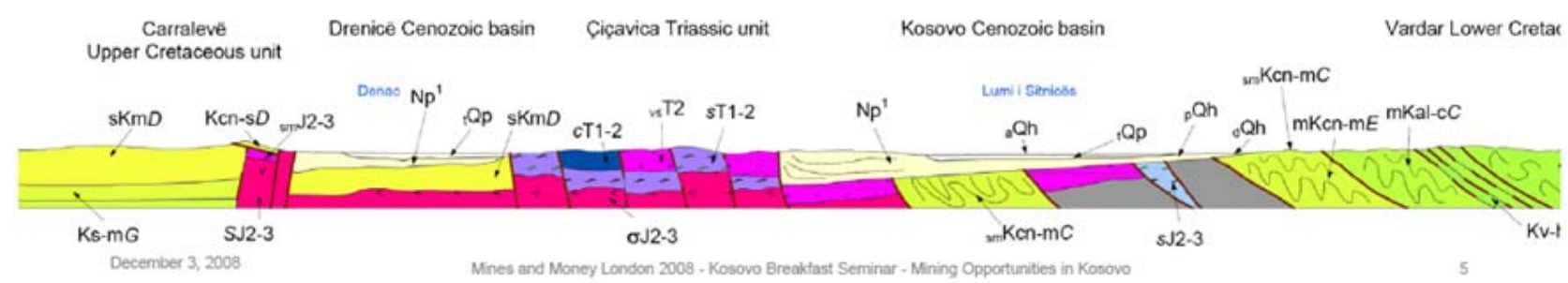

Fig. 7 Cutting the profile from the map of Kosovoz.

In 2008, Ministry of Energy and Mining, based on previously (1980’s) carried out: (i) Geophysical exploration, (ii) Geochemical sampling and (iii) Core Drilling, has identified nine areas or "Zones of Interest" that now intends to launch for a competitive tendering or licensing process.

Following the 2006/2007 Airborne Geophysical Survey, it can be confirmed that these areas corresponds with zones with geophysical anomalies. It can also be stated that the areas surrounding the "Zones of Interest” are found to be highly prospective.

Procedures for competitive tendering are currently being developed, based on model used for the "Sibovc" lignite mining area, which is an ongoing lignite mining/power project undertaken by Government of Kosovo and supported by The World Bank, European Commission and USAID.

Zones of special interest typically have "hot" geophysical characteristics and Vllahi-Zjace: Commodity: Pb-Zn; g p y drilling or other geophysical survey data.

Karace: Commodity: Pb-Zn;

Baks: Commodity: Ni;

Terstenik: Commodity: Ni;

Bushince Bolevc : Commodity: Pb-Zn;

Koretishes: Commodity: Pb-Zn;

Zhegovcit: Commodity: Pb-Zn;

Debelde: Quartzite;

Medvec-Halilaq: Magne.

\section{Conclusions}

Kosova is reach in mineral resources, particularly lead, zink, lignite, ferronickel, bauxites, etc. Existing mining industry represents great potential for private investment. Mining industry is one of our traditions. Kosova is open to further explore its mineral resources. Kosova has a very Investor Friendly Mining Regulation. Kosova's mining and minerals sector is very attractive for private investors. Kosova Government is committed to encourage private investors.

As a result of Airborne Geophysical Survey, the zones are localized in the Kosova territory by which can be continued with detailed surveys by drillings.

\section{References}

[1] Geological Survey of Finland (GTK) and British Geological Survey (BGS). http://www.bgs.ac.uk.

[2] ICMM Archive. Klingelé, E., Kahle, H.-G., Geiger, A. and Skaloud, J.

[3] Klingele, E., Cocard, M., Kahle, H.-G. and Halliday, M., 1997. "Kinematic GPS as a Source for Airborne Gravity Reduction: The Airborne Gravity Survey of Switzerland.” Geophysique 31: 104.

[4] Klingele, E., Halliday, M., Cocard, M. and Kahle, H. -G. 1995. "Airborne Gravimetric Survey of Switzerland." VPK 4 (95): 248-53.

[5] Verdun, J., Bayer, R., Klingele, E. E., Cerniar, M., Cocard, M. and Geiger, A. et al. 1999. "The Alpine Swiss French Airborne Gravimetry Project (ASFAG).” Boll. Geof. Teor. Appl. 40: 273-6.

[6] Verdun, J., Bayer, R., Klingele, E. E., Cocard, M. and Geiger, A. 2001. “Airborne Gravimetry Measurements in Montaneous Areas by Using a LaCoste and Romberg AirSea Gravimeter.” Geophysics 67 (3): 807-16.

[7] Verdun, J., Klingele, E. E., Bayer, R., Cocard, M. and Geiger, A. 2003. "The Alpine Swiss French Airborne Gravity Survey.” Geoph. J. Int. 152: 8-19. 